\title{
PENGETAHUAN DAN SIKAP DALAM PELAKSANAAN SANITASI TOTAL BERBASIS MASYARAKAT (STBM) DI KABUPATEN DONGGALA
}

\author{
Knowledge and Attitude In The Implementation of Community Led Total Sanitation \\ (CLTS) In Donggala District
}

\author{
Dedi Mahyudin Syam \\ Poltekkes Kemenkes Palu \\ (dmahyudin21@gmail.com)
}

\begin{abstract}
ABSTRAK
Sanitasi menjadi salah satu tujuan pembangunan berkelanjutan SDGs. Sanitasi total berbasis Masyarakat (STBM) adalah pendekatan perubahan perilaku pedesaan yang diterapkan secara luas untuk mengakhiri buang air besar sembarangan. Kelima pilar STBM diantaranya: tidak ada buang air besar sembarangan BABS, cuci tangan pakai sabun (CTPS), pengamanan air bersih, pengolahan air limbah, dan pengelolaan sampah. Tujuan penelitian ini adalah untuk menganalisis hubungan pengetahun dan sikap terhadap pelaksanaan tidak BABS, CTPS dan Pengamanan sampah. Metode; jenis penelitian analitik pendekatan cross sectional di Puskesmas Batusuya Kabupaten Donggala tanggal 12 Mei-10 Juni 2019. Populasi adalah kepala keluarga penduduk wilayah Puskesmas Batusuya dengan jumlah sampel 93 orang. Pengambilan sampel secara proporsional random sampling. Analisis data menggunakan uji chi square dan regresi logistik nilai kemaknaan 0,05 dan tingkat kepercayaan 95\%. Pengetahuan, sikap responden diperoleh melalui wawancara langsung dengan kuesioner yang telah diujicoba, dianalisis dengan menggunakan chi-square dan regresi logistik. Hasil penelitian menunjukkan pengetahuan cuci tangan pakai sabun (p-value 0,046 OR CI95\% 3,49 (1,02-12,00), sikap positif untuk tidak buang air besar sembarangan (p-value: 0,017 OR CI95\% 5,07 (1,343-19,19) dan sikap positif pengamanan sampah (p-value: 0,002 OR CI95\% 12,75 (2,616-62,16) merupakan determinan dari perilaku STBM di wilayah kerja Puskesmas Batusuya Kabupaten Donggala. Kesimpulan; Pengetahuan cuci tangan pakai sabun, sikap positif untuk tidak buang air besar sembarangan dan sikap positif pengamanan sampah merupakan determinan dari perilaku STBM di wilayah kerja Puskesmas Batusuya Kabupaten Donggala.
\end{abstract}

Kata kunci : STBM, CTPS, BABS

\section{ABSTRACT}

Sanitation is one of the SDGs sustainable development goals. Community led total sanitation (CLTS) is a rural protection approach that is applied for large indiscriminate water release. The five CLTS pillars were sent: no open defecation in open defecation, washing hands with soap, securing clean water, treating wastewater, and managing waste. Aim research was to analyze the relationship between knowledge and attitudes towards no open defecation, CLTS and waste safety. Method; type analytic research study cross sectional study at Batusuya Public Health Center in Donggala Regency on May 12-June 10 2019. Population is the head of the family of Batusuya Public Health Center area with a sample of 93 people. Sampling by proportional random sampling. Data analysis using chi square test and logistic regression significance value of 0.05 and $95 \%$ confidence level. Knowledge, attitudes of respondents were obtained through direct interviews with a questionnaire that was tested, analyzed using chi-square and logistic regression. The results showed knowledge of washing hands with soap (pvalue 0.046 OR CI95\% 3.49 (1.02-12.00), a positive attitude not to defecate carelessly ( $p$-value: 0.017 OR CI95\% $5.07(1,343-19,19)$ and the positive attitude of waste protection (p-value: 0.002 OR CI95\% 12.75 (2,616-62.16) is a determinant of the CLTS policy in the work area of the Batusuya Community Health Center in Donggala Regency. Positive attitude is not to dispose of air the carelessness and positive attitude of waste management are the determinants of CLTS behavior in the work area of the Batusuya Community Health Center in Donggala Regency.

Keywords CLTS, Washing Hands With Soap, Open Defecation. 


\section{PENDAHULUAN}

Sanitasi menjadi salah satu tujuan pembangunan berkelanjutan SDGs meskipun dilapangan menunjukkan kemajuan yang masih lambat ${ }^{(1)}$. Strategi Nasional Kebijakan STBM mengacu pada strategi percepatan yang bertujuan untuk mengejar target $\mathrm{SDGs}^{(2)}$. Faktanya, Sekitar 2,3 miliar orang di negara berkembang masih kekurangan akses ke fasilitas sanitasi yang lebih baik dan hampir satu miliar orang melakukan buang air besar sembarangan. Sanitasi Total Berbasis Masyarakat (STBM) menjadi pendekatan yang sangat populer dan digunakan lebih dari 60 negara. STBM adalah pendekatan perubahan perilaku pedesaan yang diterapkan secara luas untuk mengakhiri buang air besar sembarangan $^{(3-6)}$ dan masalah ini terkait kesehatan $^{(6)}$ Diakui, pendekatan revolusioner ini hemat biaya. Umumnya STBM digunakan untuk mempromosikan sanitasi di lingkungan masyarakat berpenghasilan rendah ${ }^{(7)}$.

Manfaat STBM terbukti meningkat bila dikombinasikan dengan program intervensi terpadu lainnya misalnya kemoterapi preventif, dan pendidikan Kesehatan. STBM terbukti mengurangi prevalensi infeksi cacing dan protozoa usus $^{(5)}$ dimana penyakit berbasis lingkungan di negara berkembang terutama disebabkan oleh sanitasi yang buruk dan perilaku higienis yang rendah $^{(8)}$. Salah satu indikator STBM adalah program stop buang air besar sembarangan. Program ini terbukti mencegah stunting anak baduta di Kabupaten Banggai dan Sigi ${ }^{(9)}$. Dalam upaya kampanye kesehatan, keberhasilan intervensi program berhubungan dengan akses rumah tangga ke jamban yang lebih baik termasuk status ekonomi rumah tangga, tingkat pendidikan kepala rumah tangga dan lokasi geografis rumah tangga ${ }^{(10)}$. Perpaduan pendidikan sanitasi, peraturan dan penegakan berperan penting dalam meningkatkan kesadaran masyarakat, mengubah perilaku kolektif, membuat orang mematuhi hukum sanitasi desa, dan keberhasilan keseluruhan dalam kampanye sanitasi $^{(1)}$. Termasuk juga pemanfaatan media seperti flipchart dan spanduk bermanfaat meningkatkan pesan-pesan kesehatan ${ }^{(11)}$.

Peraturan Menteri Kesehatan Republik Indonesia Nomor 3 Tahun 2014 tentang "5 Pilar STBM", yaitu Stop Buang Air Besar, Cuci
Tangan Pakai Sabun, Pengelolaan Air Minum dan Makanan Rumah Tangga, Pengamanan Limbah Rumah Tangga, dan Pengamanan Rumah Tangga Limbah Cair. Kelima pilar di atas bertujuan untuk memutus rantai penularan penyakit berbasis lingkungan dan keracunan karena manajemen makanan yang tidak tepat dan memanifestasikan masing-masing poin di atas dalam kehidupan pernikahan. Melalui kebijakan ini, Pemerintah berusaha menghilangkan salah satu faktor risiko tidak langsung untuk Stunting(12). Program ini sebaiknya dilaksanakan secara bersamaan untuk menilai dampak dari masalah yang berhubungan dengan kesehatan ${ }^{(13)}$.

Belajar dari implementasi dan hasil STBM di daerah kumuh perkotaan di kota Bandung menunjukkan bahwa pengetahuan, sikap dan niat berbeda secara signifikan sebelum dan setelah kegiatan pemicuan $(\mathrm{p}=0,006 ; 0,021$; 0,001 ). Faktor-faktor predisposisi dibangun oleh pengetahuan, sikap, niat, dan kebiasaan masyarakat. Faktor-faktor pendukung terdiri dari kondisi lingkungan, kemampuan petugas, sumber daya, agen enabler, aksesibilitas, teknologi tepat guna, dan fasilitas sanitasi. Faktor-faktor penguat terdiri dari pengetahuan dan sikap petugas, peraturan, kebijakan, dan dukungan eksternal. Namun, tindak lanjut satu tahun setelah kegiatan memicu membuktikan bahwa perubahan pada pengetahuan, sikap, niat tidak tercapai dengan tindakan masyarakat tanpa pengawasan oleh kepemimpinan lokal yang kuat, fasilitasi pemerintah dan dukungan keluarga. Kegiatan pemicu pada program STBM dapat meningkatkan pengetahuan, sikap dan niat tetapi pemantauan evaluasi intensif dan pengawasan harus dilakukan setelah implementasi ${ }^{(8)}$.

Kecamatan Sindue Tombusabora Kabupaten Donggala terdiri dari 6 desa, yaitu Desa Tibo, Desa Batusuya Goo, Desa Kaliburu, Desa Kaliburu Kata, Desa Batusuya dan Desa Saloya dengan jumlah penduduk 12.118 jiwa dengan jumlah rumah tangga 3.277. Kecamatan tersebut telah mencanangkan sanitasi total berbasis masyarakat sejak tahun 2012. Desa Saloya merupakan desa dengan kepemilikan jamban yang paling sedikit. Desa Tibo dengan jumlah 532 rumah tangga, cakupannya 405 (76,12\%). Desa Batusuya dengan jumlah 482 rumah tangga, cakupannya $408(84,4 \%)$. Desa Kaliburu dengan jumlah 568 rumah tangga, 
cakupannya 472 (83,09\%). Desa Kaliburu Kata dengan jumlah 572 rumah tangga, cakupannya 457 (79,89\%). Desa Saloya dengan jumlah 549 rumah tangga, cakupannya $268 \quad(48,81 \%)$ rumah tangga.

Belum adanya publikasi tentang pengetahun dan sikap terhadap 3 (tiga) indikator STBM di Donggala mendasari penelitian ini dilaksanakan. Tujuan penelitian ini adalah untuk menganalisis hubungan pengetahun dan sikap terhadap pelaksanaan tidak buang air besar sembarang (BABS), cuci tangan pakai sabun (CTPS) dan pengamanan sampah.

\section{METODE PENELITIAN}

Jenis penelitian analitik pendekatan cross sectional dilaksanakan di Puskesmas Batusuya Kabupaten Donggala tanggal 12 Mei-10 Juni 2019. Populasi dalam penelitian adalah kepala keluarga penduduk wilayah Puskesmas Batusuya berjumlah 12.118 jiwa. Sampel pada penelitian ini yaitu 93. Pengambilan sampel secara proporsional random sampling. analisis data menggunakan uji chi square nilai kemaknaan 0,05 dan tingkat kepercayaan 95\%.

Variabel teliti meliputi 3 indikator STBM yaitu; buang air besar sembarangan, cuci tangan pakai sabun dan pengamanan sampah rumah tangga. pengetahuan, sikap responden diperoleh melalui wawancara langsung dengan kuesioner yang telah diujicoba, dianalisis dengan menggunakan chi-square dan regresi logistik. Data disajikan dalam bentuk tabel dan narasi.

\section{HASIL}

Tabel 1 menunjukkan bahwa pada umumnya responden penelitian berumur $>45$ tahun sebanyak $83,9 \%$ berjenis kelamin lakilaki $79,6 \%$, bekerja sebagai petani $46,2 \%$ dengan latar belakang pendidikan SMA 50,5\%. Pada tabel 2 hasil temuan dari penelitian ini menunjukkan bahwa pengetahuan responden yang baik tentang BABS, CTPS dan pengamanan sampah berturut turut sebesar $63,4 \%, 69,9 \%$ dan $60,2 \%$. Adapun sikap positif responden tentang BABS, CTPS dan pengamanan sampah berturut turut sebesar $69,9 \%, 67,7 \%$ dan $64,5 \%$. Responden yang tidak melaksanakan BABS, melaksanakan CTPS dan melaksanakan pengamanan sampah berturut turut sebesar $66,7 \%, 49,5 \%$ dan $45,2 \%$.

Tabel 1. Karakteristik Umur, Jenis Kelamin, Pendidikan dan Pekerjaan Responden di Wilayah Kerja Puskesmas Batusuya Kabupaten Donggala

\begin{tabular}{lcc}
\hline \multicolumn{1}{c}{ Wilayah } & n & \% \\
\hline Umur & & \\
25-35 tahun & 5 & 5,4 \\
36-45 tahun & 10 & 10,7 \\
>45 tahun & 78 & 83,9 \\
Jenis Kelamin & & \\
$\quad$ Laki-Laki & 74 & 79,6 \\
Perempuan & 19 & 20,4 \\
Pekerjaan & & \\
Tani & 43 & 46,2 \\
Wiraswasta & 30 & 32,3 \\
PNS & 20 & 21,5 \\
Pendidikan & & \\
SD & 11 & 11,8 \\
SMP & 17 & 18,3 \\
SMA & 47 & 50,5 \\
Perguruan Tinggi & 18 & 19,4 \\
\hline Total & $\mathbf{9 3}$ & $\mathbf{1 0 0}$ \\
\hline Sumber: Data Primer, 2019 & &
\end{tabular}

Sumber: Data Primer, 2019

Tabel 2. Distribusi Pengetahuan dan Sikap Masyarakat terhadap Tidak Buang Air Besar Sembarangan, Cuci Tangan Pakai Sabun dan Pengamanan Sampah di Wilayah Kerja Puskesmas Batusuya Kabupaten Donggala

\begin{tabular}{|c|c|c|c|c|c|c|}
\hline \multirow[t]{2}{*}{ Variabel } & \multicolumn{2}{|c|}{ Tidak BABS } & \multicolumn{2}{|c|}{ CTPS } & \multicolumn{2}{|c|}{ Pengamanan sampah } \\
\hline & $\mathbf{n}$ & $\%$ & $\mathbf{n}$ & $\%$ & $\mathbf{n}$ & $\%$ \\
\hline \multicolumn{7}{|l|}{ Pengetahuan } \\
\hline Baik & 59 & 63,4 & 65 & 69,9 & 56 & 60,2 \\
\hline Cukup & 21 & 22,6 & 18 & 19,4 & 29 & 31,2 \\
\hline Kurang & 13 & 14,0 & 10 & 10,8 & 8 & 8,6 \\
\hline \multicolumn{7}{|l|}{ Sikap } \\
\hline Positif & 65 & 69,9 & 63 & 67,7 & 60 & 64,5 \\
\hline Negatif & 18 & 30,1 & 30 & 32,3 & 33 & 35,5 \\
\hline \multicolumn{7}{|l|}{ Pelaksanaan } \\
\hline Tidak melaksanakan & 31 & 33,3 & 47 & 50,5 & 51 & 54,8 \\
\hline Melaksanakan & 62 & 66,7 & 46 & 49,5 & 42 & 45,2 \\
\hline
\end{tabular}

Sumber: Data Primer, 2019 
Tabel 3. Hubungan Pengetahuan dan Sikap Masyarakat terhadap tidak Buang Air Besar Sembarangan, Cuci Tangan Pakai Sabun dan Pengamanan Sampah di Wilayah Kerja Puskesmas Batusuya Kabupaten Donggala

\begin{tabular}{|c|c|c|c|c|c|c|c|c|c|}
\hline \multirow[t]{2}{*}{ Variabel } & \multicolumn{3}{|c|}{ Tidak BABS } & \multicolumn{2}{|c|}{$\begin{array}{c}\text { Melaksanakan } \\
\text { CTPS } \\
\end{array}$} & \multicolumn{4}{|c|}{$\begin{array}{c}\text { Melaksanakan Pengamanan } \\
\text { sampah }\end{array}$} \\
\hline & $n$ & $\%$ & p-Value & $\mathrm{n}$ & $\%$ & p-Value & $\mathrm{n}$ & $\%$ & p-Value \\
\hline \multicolumn{10}{|l|}{ Pengetahuan } \\
\hline Baik & 12 & 20,3 & \multirow{3}{*}{0,001} & 41 & 63,1 & \multirow{3}{*}{0,000} & 43 & 76,8 & \multirow{3}{*}{0,000} \\
\hline Cukup & 11 & 52,1 & & 5 & 27,8 & & 4 & 13,8 & \\
\hline Kurang & 8 & 61,5 & & 1 & 10,0 & & 4 & 50,0 & \\
\hline \multicolumn{10}{|l|}{ Sikap } \\
\hline Positif & 13 & 20,0 & 0,000 & 39 & 61,9 & 0,001 & 45 & 75 & 0,000 \\
\hline Negatif & 18 & 64,3 & & 8 & 22,8 & & 6 & 18,2 & \\
\hline
\end{tabular}

Sumber: Data Primer, 2019

Tabel 4. Uji Regresi Logistik Pengetahuan dan Sikap Masyarakat terhadap tidak Buang Air Besar Sembarangan, Cuci Tangan Pakai Sabun dan Pengamanan Sampah di Wilayah Kerja Puskesmas Batusuya Kabupaten Donggala

\begin{tabular}{clcl}
\hline Variabel & Indikator STBM & p-value & OR $(\boldsymbol{C I 9 5 \% )}$ \\
\hline Pengetahuan & BABS & 0,457 & $1,38(0,58-3,25)$ \\
& CTPS & 0,046 & $3,49(1,02-12,00)$ \\
\multirow{2}{*}{ Sikap } & Pengamanan sampah & 0,925 & $1,05(0,33-3,38)$ \\
& BABS & 0,017 & $5,07(1,343-19,19)$ \\
& CTPS & 0,721 & $1,31(0,291-5,94)$ \\
& Pengamanan sampah & 0,002 & $12,75(2,616-62,16)$ \\
\hline
\end{tabular}

Sumber: Data Primer, 2019

Pada tabel 3, hasil analisis chi-square, menunjukkan bahwa pengetahuan berpengaruh terhadap pelaksanaan perilaku tidak buang air besar sembarang (BABS), cuci tangan pakai sabun (CTPS) dan pengamanan sampah dengan p-value masing-masing $0,001,0,000,0,000$. Begitupula dengan sikap, sikap berpengaruh terhadap pelaksanaan perilaku tidak buang air besar sembarang (BABS), cuci tangan pakai sabun (CTPS) dan pengamanan sampah dengan nilai $p$-value; $0,000,0,001,0,000$.

Tabel 4 menunjukkan hasil Uji Regresi Logistik diantara ketiga indikator, pengetahuan CTPS merupakan determinan dari perilaku STBM di wilayah kerja Puskesmas Batusuya Kabupaten Donggala dengan p-value 0,046 dan OR CI95\% sebesar 3,49 (1,02-12,00). Sementara dari aspek sikap. Variabel yang berpengaruh adalah sikap positif untuk tidak BABS dengan p-value: 0,017 dan OR CI95\% sebesar 5,07 (1,343-19,19). Begitupula dengan sikap positif pengamanan sampah dengan p-value: 0,002 OR CI95\% sebesar 12,75 $(2,616-62,16)$.

\section{PEMBAHASAN}

Hasil penelitian ini menunjukkan bahwa pengetahuan cuci tangan pakai sabun, sikap positif untuk tidak buang air besar sembarangan dan sikap positif pengamanan sampah merupakan determinan dari perilaku STBM di wilayah kerja Puskesmas Batusuya Kabupaten Donggala. Karakteristik responden yang dapat diamati dari penelitian ini adalah pada umumnya responden berumur $>45$ tahun, dominan berjenis kelamin laki-laki, bekerja sebagai petani dengan latar belakang Pendidikan SMA. Hasil temuan penelitian ini juga menunjukkan bahwa pengetahuan responden yang baik tentang stop BABS, CTPS dan pengamanan sampah berkisar 60,2\%$69,9 \%$. Adapun sikap positif responden tentang stop BABS, CTPS dan pengamanan sampah berkisar 64,5\%-69,9\%. Responden yang tidak melaksanakan BABS, melaksanakan CTPS dan melaksanakan pengamanan berkisar 45,2\%$66,7 \%$. Rerata aspek pengetahuan dan sikap lebih tinggi dari aspek pelaksanaan. Hal ini berarti dalam pelaksanaan ada faktor lain yang berperan selain pengetahuann dan sikap yang belum diteliti dalam penelitian ini.

Responden yang memiliki pengetahuan 
CTPS yang baik berpeluang 3,49 kali untuk melaksanakan perilaku CTPS dibanding yang berpengetahuan kurang, sedangkan responden yang memiliki sikap positif untuk tidak BABS berpeluang 5,07 kali melaksanakan perilaku stop BABS dan responden yang memiliki sikap positif pengamanan sampah berpeluang 12,7 kali untuk melaksanakan pengamanan sampah dibanding responden yang bersikap negatif dalam pengamanan sampah.

Belajar dari studi Sitra (2019) dimana pelaksanaan program STBM dimulai dari perencanaan, pelaksanaan, pemantauan dan evaluasi masyarakat yang terlibat. Masyarakat diberi peran utama dalam program ini. Peran Pemerintah dalam program hanya memfasilitasi STBM yang pada akhirnya sepenuhnya diserahkan kepada swadaya masyarakat. Program STBM telah berhasil mengubah pengetahuan dan sikap terhadap buang air besar sembarangan dan Sabun Cuci Tangan, tetapi belum berhasil mengubah perilaku masyarakat secara keseluruhan ${ }^{(14)}$.

Analisis mediasi Harter dkk (2018) mengungkapkan bahwa hubungan partisipasi STBM dengan kemungkinan memiliki jamban dimediasi oleh faktor konteks sosial dan faktor penentu psikososial. Kemungkinan membangun jamban tergantung pada faktor konteks sosial yang ada di desa, perilaku orang lain di masyarakat, persetujuan orang lain tentang kepemilikan jamban, kepercayaan diri pribadi dalam membangun jamban, dan ketepatan komunikasi tentang manfaat kepemilikan jamban selama acara pemicu STBM $^{(6)}$.

Belajar dari studi Hurlimann (2018) menunjukkan bahwa intervensi program terpadu secara signifikan berdampak pada penggunaan jamban yang dilaporkan (sebelum intervensi sebesar $15,5 \%$ dan meningkat setelah intervensi menjadi $94,6 \%$, perilaku buang air besar di lingkungan masyarakat yang sebelumnya sebesar $75,0 \%$ menurun menjadi $16,7 \%$. Kesadaran akan kontaminasi lingkungan melalui buang air besar sembarangan yang sebelumnya hanya $20,4 \%$ meningkat menjadi $52,2 \%{ }^{(5)}$.

Dalam konteks pembangunan jamban setelah bencana, pelajaran dari Mozambik Utara menunjukkan bahwa setelah kejadian bencana pembangunan kembali jamban tergantung pada pendidikan, kondisi tanah, kohesi sosial, dan perasaan aman dari diare, persepsi bahwa banyak anggota masyarakat lainnya memiliki jamban dan kepercayaan diri yang tinggi pada kemampuan pribadi untuk memperbaiki atau membangun kembali sebuah kakus yang rusak ${ }^{(15)}$.

Pendekatan dengan pemicuan terbukti dari studi Sesan, dkk (2018) yang menyoroti pentingnya lingkungan yang memungkinkan, pendekatan yang berfokus pada masyarakat, dan faktor kontekstual spesifik lokal dalam mempromosikan perubahan perilaku di sektor sanitasi(16). STBM sangat penting untuk arah kebijakan. Belajar dari Porgram di Ghana bahwa biaya dan efek yang dihasilkan dari HPI diperiksa dengan menggunakan studi kasus dari empat komunitas. Peningkatan perilaku higienis secara statistik dikaitkan dengan investasi pemerintah $(p<0,001)$ dan investasi rumah tangga $(p<0,001)$. Biaya aktual HPI adalah US \$ 90 per rumah tangga: US \$ 51 dan 39 masing-masing dari pemerintah dan rumah tangga. Efektivitas biaya HPI adalah US \$ 106,42 per kapita dari perilaku kebersihan yang ditingkatkan ${ }^{(17)}$.

Dalam konteks yang lebih kecil, belajar dari studi Rumajar dkk (2019) menunjukkan bahwa tingkat kepuasan masyarakat terhadap program STBM stop BABS sebesar 80\%(18). Studi Tutuanita dkk (2019) menunjukkan korelasi negatif yang signifikan antara buang air besar sembarangan dan akses sanitasi $(\mathrm{r}=-0.975)$. Namun, tidak ada korelasi yang signifikan antara diare dan akses sanitasi $(\mathrm{r}=-$ 0,102 ) dan antara diare dan buang air besar terbuka $(r=0,124)$, menunjukkan korelasi yang signifikan antara buang air besar sembarangan dan sanitasi, sehingga Nampak bahwa memang STBM harus dilaksanakan secara bersamaan untuk menilai dampak dari masalah yang berhubungan dengan kesehatan, terutama $\left.\operatorname{diare}^{(13}\right)$.

Dalam konteks perilaku CTPS di sekolah, studi Sapriana (2020) menunjukkan bahwa terdapat peningkatan dari $30,61 \%$ menjadi $67,34 \%$ siswa yang sering mencuci tangan saat berada di sekolah setelah tersedia sarana CTPS, penggunaan sabun saat cuci tangan menggunakan air mengalir meningkat dari $30,61 \%$ menjadi $87,75 \%$. Hal ini menunjukkan bahwa ketersediaan sarana CTPS efektif terhadap praktik CTPS di sekolah dasar ${ }^{(19)}$.

Pertimbangan tentang tradisi dapat 
dipelajari dari studi Leong (2020) dimana pada penelitian narasi sanitasi dua tema utama; yang pertama menggambarkan "masyarakat teknologi" dengan wacana tentang kesehatan, modernitas dan infrastruktur; yang kedua "masyarakat hijau" dengan wacana tentang tradisi, kedekatan dengan alam dan perilaku praktis, yang memberikan narasi kuat yang dapat dipertahankan untuk BABS. Memahami pandangan dunia yang bersaing tentang lingkungan ini memberi para pembuat kebijakan premis yang baik untuk memotivasi penggunaan jamban saat India melakukan urbanisasi. Ini juga menjelaskan kegagalan metode CLTS yang mengandalkan "malu" dan "jijik" untuk memotivasi perubahan perilaku jangka panjang ${ }^{(20)}$.

Pada akhirnya, penelitian ini telah memberikan informasi penting bahwa bila program STBM di Batusuya Donggala akan dilaksanakan maka aspek pengetahuan pengetahuan masyarakat tentang cuci tangan pakai sabun, sikap positif untuk tidak buang air besar sembarangan dan sikap positif pengamanan sampah telah menjadi modal utama untuk kesuksesan program STBM di wilayah tersebut. Harapannya dengan pelaksanaan STBM akan mempermudah upaya meningkatkan akses sanitasi masyarakat yang lebih baik sehingga dalam jangka panjang dapat menurunkan angka kesakitan dan kematian yang diakibatkan oleh sanitasi yang kurang baik ${ }^{(21)}$.

\section{KESIMPULAN DAN SARAN}

Pengetahuan cuci tangan pakai sabun, sikap positif untuk tidak buang air besar sembarangan dan sikap positif pengamanan sampah merupakan determinan dari perilaku STBM di wilayah kerja Puskesmas Batusuya Kabupaten Donggala. Edukasi tentang STBM perlu menempatkan pengetahuan cuci tangan pakai sabun, sikap positif untuk tidak buang air besar sembarangan dan sikap positif pengamanan sampah sebagai jembatan perilaku STBM di Kabupaten Donggala.

\section{UCAPAN TERIMA KASIH}

Terima kasih kepada Direktur Poltekkes Kemenkes Palu, Kepala Dinas Kesehatan Donggala dan Kepala Puskesmas Batusuya atas ijin penelitian yang telah diberikan serta kepada seluruh responden penelitian yang telah terlibat.

\section{DAFTAR PUSTAKA}

1. Safari J, Mohamed H, Dimoso P, Akyoo W, Odhiambo F, Mpete R, et al. Lessons learned from the national sanitation campaign in Njombe district, Tanzania. J Water, Sanit Hyg Dev. 2019 Dec 1;9(4):754-64.

2. Pramiasih T, Hernawati S, Ma'rufi I. An Evaluation on Implemention of STBM Program Pillar 1 to Decrease of Diarrhea at ODF Village (Reinforcing Factors on Precede - Proceed) in Bondowoso District. Heal Nations. 2019;3(7):321-8.

3. Ficek F, Novotný J. Comprehending practitioners' assessments of community-led total sanitation. Health Promot Int. 2019 Dec 1;34(6):e129-38.

4. Venkataramanan V, Crocker J, Karon A, Bartram J. Community-Led Total Sanitation: A Mixed-Methods Systematic Review of Evidence and Its Quality. Environ Health Perspect. 2018 Feb 2;126(2):26001.

5. Hürlimann E, Silué KD, Zouzou F, Ouattara M, Schmidlin T, Yapi RB, et al. Effect of an integrated intervention package of preventive chemotherapy, community-led total sanitation and health education on the prevalence of helminth and intestinal protozoa infections in Côte d'Ivoire. Parasit Vectors. 2018 Feb 27;11(1):115.

6. Harter M, Mosch S, Mosler H-J. How does Community-Led Total Sanitation (CLTS) affect latrine ownership? A quantitative case study from Mozambique. BMC Public Health. 2018 Mar 21;18(1):387.

7. Biran A, Danquah L, Chunga J, Schmidt WP, Holm R, Itimu-Phiri A, et al. A ClusterRandomized Trial to Evaluate the Impact of an Inclusive, Community-Led Total Sanitation Intervention on Sanitation Access for People with Disabilities in Malawi. Am J Trop Med Hyg. 2018/02/01. 2018 Apr;98(4):984-94.

8. Sari SYI, Setiadi AA, Sanjaya DK, Raksanagara AS. Community-Led Total Sanitation Program Attain to Increase Knowledge, Attitude and Intention but Fail to Change the Community's Behavior; Case Study in Urban Slum Area in Bandung Municipality. IOP Conf Ser Earth Environ Sci. 2019 Apr 30;248(1):012007.

9. Hafid F, Djabu U, Udin, Nasrul. Efek Program SBABS Terhadap Pencegahan Stunting Anak Baduta di Kabupaten Banggai dan Sigi. Indones J Hum Nutr. 2017;4(2):79-87.

10. Mwakitalima A, Massa K, Seleman A, Kassile T. Scaling up rural sanitation in Tanzania: evidence from the National 
Sanitation Campaign. J Water, Sanit Hyg Dev. 2018 Jun 1;8(2):290-306.

11. Nasrul, Zainul, Hafid F, Taqwin. Manfaat Media Flipchart dan Spanduk dalam Perilaku Kesehatan 1000 HPK di Sulawesi Tengah. Media Kesehat Masy Indones. 2018;14(1):52-60.

12. Fadilah M. "Bonus of Demography" as an Opportunity to Build Indonesian's Welfare (Through the Role of Doctors in Primary Care in the STBM Program for Decreasing the Prevalence of Stunting). Rev Prim Care Pract Educ (Kajian Prakt dan Pendidik Layanan Prim. 2019;2(3):92.

13. Tutuanita NNY, Zakianis. Sanitation, Open Defecation, and Diarrhea in Tangerang, Banten, Indonesia, in early 2017: A CrossSectional Epidemiological Study. J Int Dent Med Res. 2019;12(1):368-71.

14. Sitra E, Agustar A, Erwin. Pelaksanaan Program Sanitasi Total Berbasis Masyarakat (Stbm) dan Implikasinya Terhadap Perubahan Perilaku Masyarakat Di Kabupaten Lima Puluh Kota. Jispo. 2019;9(1):344-55.

15. Mosler H-J, Mosch S, Harter M. Is Community-Led Total Sanitation connected to the rebuilding of latrines? Quantitative evidence from Mozambique. PLoS One.
2018 May 22;13(5):e0197483-e0197483.

16. Sesan T, Jewitt S, Clifford M, Ray C. Toilet training: what can the cookstove sector learn from improved sanitation promotion? Int J Environ Health Res. 2018 Nov 2;28(6):66782.

17. Woode PK, Dwumfour-Asare B, Nyarko $\mathrm{KB}$, Appiah-Effah E. Cost and effectiveness of water, sanitation and hygiene promotion intervention in Ghana: the case of four communities in the Brong Ahafo region. Heliyon. 2018 Oct;4(10):e00841.

18. Rumajar PD, Katiandagho D, Robert D. Analisis Tingkat Keberhasilan Pelaksanaan Program Sanitasi Total Berbasis Masyarakat (STBM) di Wilayah Kerja Puskesmas Manganitu Kabupaten Kelp.Sangihe (Studi di Desa Taloarane I). Jkl. 2019;9(1).

19. Sapriana S, Maryam, Arianty R. Pengaruh Ketersediaan Sarana terhadap Praktik Cuci Tangan Pakai Sabun (CTPS) Siswa Sekolah Dasar. Poltekita J Ilmu Kesehat. 2020 May 20;14(1):24-9.

20. Leong C. Narratives of sanitation: Motivating toilet use in India. Geoforum. 2020 May;111:24-38.

21. Surya J. Sanitasi Total Berbasis Masyarakat (STBM Dengan Diare Pada Balita. J Ilm Kesehat Sandi Husada. 2019;10(2):281-4. 